\title{
O ensino da produção de texto em perspectiva dialógica: implicações para o ensino fundamental I
}

\author{
Antonio Flávio Ferreira de Oliveira ${ }^{1}$ \\ Ilderlândio Assis de Andrade Nascimento ${ }^{2}$ \\ Maria do Socorro Pereira da Silva ${ }^{3}$
}

\section{Resumo}

Este trabalho investiga a prática de ensino de produção de texto em perspectiva dialógica no Ensino Fundamental I. Mobiliza a filosofia do Círculo de Bakhtin, sobretudo Bakhtin (2011), Volóchinov $(2013,2017)$ e pontos de vista de Antunes (2003), Koch (2006), Marcuschi (2008) etc. Metodologicamente, a pesquisa é bibliográfica e aponta para conceitos que fundamentam o ensino de produção textual. Como resultado, constatou-se que a prática de ensinoaprendizagem de escrita em perspectiva dialógica evidencia aspectos relacionados com o texto como instância material da orquestração de vozes sociais.

Palavras-chave: Produção de Texto; Ensino; Perspectiva Dialógica; Ensino Fundamental I.

\section{The teaching of Text production in dialogical perspective: implications for Elementary School}

\section{Abstract}

This work investigates the textual teaching practice in dialogical perspective in Elementary School. Thus, we mobilized the Bakhtin's Circle theoretical and methodoligical approach, such as Bakhtin (2011), Volóchinov (2013, 2017), as well as conceptions of Antunes (2003), Koch (2006), Marcuschi (2008) etc. Methodologically, we did a bibliographical research and pointed to conceptual elements that ground the text production teaching. As a result, we conclued that the text production teaching-learning practice in dialogical perspective shows aspects related to the text as social voices.

Keywords: Text Production; Teaching; Dialogical Perspective; Elementary School.

\section{Considerações iniciais}

Este trabalho discute questões relacionadas com o processo de produção textual nas últimas séries dos anos iniciais do Ensino Fundamental. A escolha dessa temática se justifica devido ao fato de, através da literatura da área, termos observado vários problemas que são oriundos do resultado de uma prática pedagógica que ainda prioriza aspectos voltados para o ensino de texto em perspectiva monológica, isto é, é realizado um ensino caracterizado por usar

\footnotetext{
${ }^{1}$ Universidade Estadual da Paraíba, Guarabira-PB, flavioccaa@hotmail.com.

${ }^{2}$ Centro de Ensino Superior do Seridó - UFRN, Caicó-RN, ilderlandion@gmail.com.

${ }^{3}$ Prefeitura Municipal de Alagoinha, Alagoinha-PB, corrinhaprofessora@gmail.com.
} 
o texto apenas como pretexto para a demonstração de categorias de níveis de linguagem. Para os ditames da sociedade hodierna, essa prática dita tradicional se faz desnecessária, visto que, hoje, defende-se uma ideologia pedagógica compromissada com as práticas de letramentos sociais.

Não existe mais razão para, ainda, trabalhar o texto como produto da lógica racional do sujeito ou como produto imanente da estrutura linguística. O texto precisa ser visto como algo de maior alcance e como uma instância de interação na qual se orquestram vozes que são imbricadas nas materialidades linguísticas. É preciso considerar a construção de texto como um processo que abrange valores cognitivos, enunciativos, discursivos e linguísticos, pois é através da operação desses recursos que os sujeitos, em contexto de interação com outros sujeitos, criam/expressam suas ideias em forma de texto.

Ao pensar isso como uma possibilidade de prática educacional nas últimas séries dos anos iniciais, defendemos que o texto deve ser apresentado aos alunos como uma instância discursivo-enunciativa, na qual eles podem criar, organizar e expressar o seu dizer. Para tanto, os textos devem ser introduzidos em razão das necessidades comunicativas, tanto do período escolar como das possibilidades de uso que são exigidas desse aluno na sociedade. Essa relação de aproximação entre as demandas da escola e as da sociedade ainda não acontece de modo efetivo/adequado nos livros didáticos, haja vista questões particulares que abrangem a formação dos professores, as metodologias aplicadas, as condições prévias da formação dos alunos etc. Ainda é possível ver na literatura crítica dessa área demandas pertinentes que decorrem da irrelevância social de atividades de produção textual propostas em alguns livros didáticos. A crítica acontece em razão da falta de objetivo para o alcance de letramentos sociais, principalmente pelo fato de, nessas atividades, não serem contemplados usos da linguagem que possam alcançar o todo de sua heterogeneidade como, por exemplo, o emprego de variações mais informais do cotidiano.

Para tanto, o objetivo deste estudo é refletir a respeito do processo de produção textual em perspectiva dialógica e apontar para aspectos que sejam pertinentes no ensino dessa modalidade, no nível escolar sugerido na pesquisa. Isso posto, nos fez formular a pergunta que questiona: Quais aspectos podem ser considerados/estabelecidos no processo de ensinoaprendizagem de produção textual em perspectiva dialógica? Ao questionar, não estamos 
afirmando a não existência de propostas que contemplem a temática. No entanto, queremos apresentar uma maneira particular estabelecida pelos resultados de nossas experiências, enquanto professores dos Cursos de Letras e de Pedagogia e na Educação Básica Municipal.

Para a realização deste estudo, fizemos uma discussão teórica dos escritos de autores do Círculo de Bakhtin, tais como Bakhtin (2011), Volóchinov (2013), Volochínov (2017), e de autores contemporâneos que fundamentam suas pesquisas nessa teoria, a saber: Antunes (2003), Dolz, Noverraz e Schneuwly (2004), Koch (2006), Marcuschi (2008), Sobral (2009) etc. As propostas desses autores consolidam nossa discussão devido ao fato de consistirem em um arcabouço teórico-metodológico eficaz/adequado para o processo de ensino-aprendizagem de Língua Portuguesa, no contexto da educação em 2020. Isso é bastante evidente que, a partir dessas apreensões teóricas, formam-se as bases para documentos oficiais, como os Parâmetros Curriculares Nacionais - (PCN) e a Base Nacional Comum Curricular - (BNCC).

Assim, além da discussão teórica, este trabalho discute conceitos referentes ao texto e a sua relação com o processo de ensino-aprendizagem. Especialmente, averigua o funcionamento do enfoque dialógico no processo de ensino-aprendizagem de produção textual no Ensino Fundamental I.

\section{Texto e ensino em perspectiva dialógica}

O texto corresponde ao conjunto multissemiótico sob o qual se materializam os pontos de vista dos seres humanos. Institui a instância material criada flexivelmente para representar as ações do (inter)agir de sujeitos, constituídos conscientemente pelas valorações das diversas esferas da criação ideológica. É no texto que se evidenciam as primeiras impressões do produto das atividades humanas, visto que, nele, manifestam-se a lógica do pensamento, as emoções, as paixões e as articulações das habilidades cognitivas. No texto, cruzam-se pontos de vista, digladiam-se acordos e desacordos, refutam-se ideias, irrompem-se as mais variadas apreensões das realidades do mundo. Além do texto, não existe outro lugar discursivo-enunciativo para que se manifeste o modus operandi do ser/existir em devir de sujeitos sociais.

Esse entendimento alinha-se à postura dialógica defendida por Bakhtin, para quem o texto é compreendido como: (i) “dado primário de todas as disciplinas do pensamento filosófico- 
humanista no geral (inclusive do pensamento teológico e filosófico em sua fonte)" (BAKHTIN, 2011, p.307); e (ii) "a realidade imediata (realidade do pensamento e das vivências), a única da qual podem provir essas disciplinas e esse pensamento" (BAKHTIN, 2011, p.307). Nessa tônica, a concepção de texto se funda na ideia de que o dizer humano é realizado sob a forma de uma teia constituída de camadas. Há a camada semiótica que reflete a organização dos elementos materiais da criação e da expressão do pensamento. E também a camada discursivo-enunciativa na qual são tecidos os elementos representantes do ser, do tempo, do espaço, da ideologia e das condições que determinam a formação e a produção do dizer.

Seguindo essa linha teórico-filosófica, Koch (2006, p.15) entende/define texto como "lugar da interação", visto que, nesse lugar, os sujeitos (re)constroem seus pontos de vista em relação à vida, razão pela qual, nessa instância superficial, tomam lugar "uma gama de implícitos, dos mais variados tipos, somente detectáveis quando se tem, como pano de fundo, o contexto sociocognitivo dos participantes da interação" (KOCH, 2006, p.17). Isso comunga com o que também defende Marcuschi (2008) que, ao interpretar o pensamento de Beaugrande e Dressler $(1981)^{4}$, entende os princípios/mecanismos da textualidade como a força dialógica que, para criar sentidos, cruza os elementos da interação no texto.

Conforme apresenta Marcuschi (2008), os elementos que principiam a dialogia no texto são representados pela coesão (que articula a organização e a ordem das palavras, sentenças, parágrafos no todo do texto); pela coerência (que orquestra a produção de sentidos do texto pela relação entre sujeito e mundo); pela aceitabilidade (que trata dos acordos entre a relação de conhecimento dos (inter)locutores); informatividade (que principia a quantidade, a qualidade, o modo e a relevância da informação no texto); pela situacionalidade (que instancia o lugar, o tempo e a necessidade comunicativa dos sujeitos no texto); pela intertextualidade (que determina o diálogo entre textos); e pela intencionalidade (que trata da construção de sentido do querer dizer do sujeito-produtor no texto). Em torno do movimento dialógico no processo de produção de textos, não podemos deixar de tocar na questão de duas concepções teóricas imprescindíveis, a saber, os gêneros do discurso postulados por Bakhtin (2011) e as sequências didáticas propostas por Dolz, Noverraz e Schneuwly (2004) para trabalhar com um gênero de texto.

\footnotetext{
${ }^{4}$ BEAUGRANDE, R.; DRESSLER, W. U. Introduction to text linguistics. Londres, Longman, 1981.
} 
A primeira concepção (os gêneros do discurso) estabelece o posicionamento teórico para entender que a produção de texto deve acontecer como uma necessidade de sujeitos, os quais usam a linguagem em determinadas esferas ideológicas da sociedade. Nesse sentido, esses sujeitos produzem enunciados concretos, a partir da interação nas relações de alteridade, como respostas avaliativas que determinam a produção do dizer, especialmente, criando padrões flexíveis de organização da comunicação.

O referido autor chama a atenção para o fato de que os gêneros discursivos são compostos por três elementos constitutivos imprescindíveis: o tema, o estilo e a construção composicional (BAKHTIN, 2011). Na concepção de Sobral, ao fazer referência ao livro de Cereja $(2005)^{5}$, o tema corresponde ao "sentido concreto contextual, sentido que parte do sentido abstrato registrado nos dicionários e vai além dele" (SOBRAL, 2009, p.74). Já o estilo, para o autor supracitado, diz respeito às formas materiais do dizer (SOBRAL, 2009). E, por fim, a construção composicional está relacionada ao material com que o autor trabalha para dar acabamento provisório ao texto, sobretudo, ao "modo de dizer, de organizar os discursos" (SOBRAL, 2009, p.68).

A segunda concepção (as sequências didáticas), em conformidade com Dolz, Noverraz e Schneuwly (2004), constitui a implementação de modos didáticos para trabalhar com os gêneros de texto. Ao postular esse conceito, os autores ressaltam que sequência didática "é o conjunto de atividades escolares organizadas, de maneira sistemática, em torno de um gênero textual oral ou escrito" (DOLZ; NOVERRAZ; SCHNEUWLY, 2004, p.82). Para tanto, esse conjunto de atividades que configuram a estrutura de uma sequência didática deve ser estabelecido por: (i) a apresentação da situação da produção textual, (ii) a produção inicial, (iii) a composição sequencial de módulos, e, por fim, (iv) a produção final. Como concluem os autores mencionados, ela "tem a finalidade de ajudar o aluno a dominar melhor um gênero de texto, permitindo-Ihe, assim, escrever ou falar de uma maneira mais adequada numa dada situação de comunicação" (DOLZ; NOVERRAZ; SCHNEUWLY, 2004, p.83).

Em consonância com o que foi estabelecido nos Parâmetros Curriculares Nacionais (BRASIL, 2001), na década de 1980, houve uma quebra de paradigma com relação à aplicação e

\footnotetext{
${ }^{5}$ CEREJA, W. R. Ensino de literatura: uma proposta dialógica para o trabalho com a literatura. São Paulo: Atual, 2005.
} 
ao uso das metodologias de ensino de Língua Portuguesa. Foram abandonadas as práticas pedagógicas que priorizavam o ensino sobre a língua, cujo enfoque estava no conhecimento dos elementos estruturais, como os padrões fonéticos/fonológicos, os morfológicos, os sintáticos e os semânticos. O ensino voltado ao uso da linguagem em contextos sociais ganhou espaço, e foram adotadas metodologias fundamentadas na heterogeneidade da língua como, por exemplo, as que têm como foco as variações, as condições discursivas no processo de leitura e de escrita, as competências de usos sociais por parte dos sujeitos escritores e leitores etc. Em outras palavras, muitos pesquisadores e professores optaram por teorias linguísticas e da aprendizagem que resultavam em práticas de letramentos sociais.

A ideia de ensino de língua materna foi apoiada a partir da concepção de uso da linguagem. Assim, a prática educacional ganhou uma roupagem caracterizada pelo "compromisso com a democratização social e cultural [que] atribui à escola a função e a responsabilidade de contribuir para garantir a todos os alunos o acesso aos saberes linguísticos necessários para o exercício da cidadania" (BRASIL, 2001, p.19, grifo nosso). Nesse caso, a concepção de texto passa a ser compreendida como manifestações linguísticas do discurso, isto é, materializações do uso da linguagem em contextos sociais.

Dessa maneira, segundo os PCN, o texto ganha o caráter de "unidade de ensino e a noção de gramática como relativa ao conhecimento que o falante tem de sua linguagem [...]" (BRASIL, 2001, p.27). Nesse ponto de vista, ainda conforme o documento, "o ensino de Língua Portuguesa deve se dar num espaço em que as práticas de uso da linguagem sejam compreendidas em sua dimensão histórica" (BRASIL, 2001, p.34). Tratando disso especificamente, a prática de ensino passou a ser estabelecida pela relação “USO - REFLEXÃO - USO” (BRASIL, 2001, p.40), quer dizer, "procurando desenvolver no aluno a capacidade de compreender textos orais e escritos e de assumir a palavra, produzindo textos em situações de participação social" (BRASIL, 2001, p.40).

Essa perspectiva também é assumida por Antunes (2003, p.14), autora que pensa/teoriza o ensino de língua, buscando estimular nos professores a tomada de consciência de que devem "contribuir significativamente para que os alunos ampliem sua competência no uso oral e escrito da língua portuguesa", bem como propor a visão de que "o ensino de língua portuguesa não pode afastar-se desses propósitos cívicos de tornar as pessoas cada vez mais críticas, mais participativas e atuantes, política e socialmente" (ANTUNES, 2003, p.15). Na visão da autora, 
quem trabalha com a língua, deve pensar/propor análises linguísticas centradas no uso, visto que existe uma "regularidade do funcionamento interativo da língua, que somente acontece por meio de textos orais e escritos, em práticas discursivas as mais diversas, conforme as situações sociais em que se inserem" (ANTUNES, 2003, p 15).

Nessa perspectiva, o trabalho com a análise linguística deve se distanciar de metodologias que, ao considerar o ensino da escrita textual, visem ou aos aspectos da lógica do pensamento ou aos da imanência da língua como elementos preponderantes para consolidar o processo de ensino, de modo teórico e metodológico. Considerar isso significa compreender a escola não mais como o lugar onde se ensina texto somente sob a perspectiva da variação normativa padrão da língua, em conformidade com seu núcleo duro, isto é, seu sistema de formas fonéticas, fonológicas, sintáticas e semânticas. No entanto, a escola passa a ser entendida como o lugar do ensino da prática textual, tanto para implementar letramentos em diversas esferas sociais, quanto para efetuar o letramento de práticas escolares em nível interdisciplinar. É dessa forma que podemos cogitar a ideia de um sujeito crítico e competente linguística e discursivamente no contexto escolar e na vida cotidiana.

A partir do pensamento de Antunes (2003), elaboramos um quadro que se compõe de seis (06) princípios referentes ao ensino de escrita em perspectiva dialógica.

Quadro 1: Princípios do ensino de escrita

\begin{tabular}{|l|l|}
\hline Princípio 1 & $\begin{array}{l}\text { A escrita, como toda atividade interativa, implica uma relação cooperativa } \\
\text { entre duas ou mais pessoas. }\end{array}$ \\
\hline Princípio 2 & $\begin{array}{l}\text { A escrita, na diversidade de seus usos, cumpre funções comunicativas } \\
\text { socialmente específicas e relevantes. }\end{array}$ \\
\hline Princípio 3 & $\begin{array}{l}\text { A escrita varia, na sua forma, em decorrência das diferenças de função que } \\
\text { se propõe cumprir e, consequentemente, em decorrência dos diferentes } \\
\text { gêneros em que se realiza. }\end{array}$ \\
\hline Princípio 4 & $\begin{array}{l}\text { A escrita supõe condições de produção e recepção diferentes daquelas } \\
\text { atribuídas à fala. }\end{array}$ \\
\hline Princípio 5 & $\begin{array}{l}\text { A escrita compreende etapas distintas e integradas de realização } \\
\text { (planejamento, operação e revisão), as quais, por sua vez, implicam da } \\
\text { parte de quem escreve uma série de decisões. }\end{array}$ \\
\hline Princípio 6 & $\begin{array}{l}\text { A escrita, enquanto sistema de codificação, é regida por convenções } \\
\text { gráficas, oficialmente impostas. }\end{array}$ \\
\hline
\end{tabular}

Fonte: Aula de Português: encontro e interação (ANTUNES, 2003).

Periódico Horizontes - USF - Itatiba, SP - Brasil - e020072 
No Quadro 1, para formular apontamentos metodológicos à prática da escrita na escola, Antunes retoma pontos de vista basilares da Filosofia do Círculo de Mikhail Bakhtin, a saber:

a) no princípio 1, a relação de cooperação por meio da interação acontece em razão do postulado da alteridade do Círculo, visto que o outro constitui o elemento imprescindível para a enunciação;

b) no princípio 2, a escrita é orientada a partir das determinações dos campos ideológicos, nos quais acontecem as atividades humanas;

c) no princípio 3, é elucidada a ideia de estilo que, para Bakhtin (2011), institui a forma como deve se materializar a enunciação diante da situação;

d) no princípio 4, é evidenciada a noção de situação que, para Volochínov (2013), representa os elementos do tempo e do espaço, bem como a relação de interação entre os sujeitos (inter)locutores;

e) no princípio 5, a autora aponta para os elementos da avaliação/auscultação em razão da formulação de atitudes ativo-responsivas;

f) no princípio 6, a linguista toca na questão tanto do estilo como na da construção composicional que orientam a possibilidade de acabamento da escrita.

Dito a respeito desses conceitos, oriundos da filosofia bakhtiniana e da Linguística Textual, podemos concluir que a ideia de ensino de produção de texto, em perspectiva dialógica, corrobora uma prática pedagógica que resulta no letramento de alunos enquanto sujeitos da escola, sujeitos da família, sujeitos da vida etc. Assim, o que se prioriza é a aplicação de uma metodologia que se paute na idealização da linguagem enquanto material semiótico da criação humana (VOLOCHÍNOV, 2013), na língua como um sistema flexível de signos ideológicos (OLIVEIRA, 2019) e na noção de uso como fator primordial para as condições de produção textual.

Implicações da perspectiva dialógica da linguagem no ensino de produção textual nas últimas séries dos anos iniciais do Ensino Fundamental

A perspectiva dialógica da linguagem, conforme mostrado no Quadro 1, traz consequências significativas no modo como encaramos o ensino de produção de texto no Ensino Fundamental I, pois propõe uma postura diferenciada diante do objeto de ensino, dos sujeitos 
envolvidos e dos espaços sociais onde ocorre o processo de ensino-aprendizagem. Desse modo, o ensino de produção textual precisa considerar o texto como unidade de sentido, ou seja, como o ponto de partida e de chegada em aulas de língua materna. Não há aula de produção de texto sem texto. A questão é, portanto, o tipo de tratamento que é dado ao texto no espaço escolar, pois ele pode ser usado apenas como pretexto para o ensino descontextualizado de gramática e conceitos oriundos dos manuais de gramáticas e não como um ato de interação verbal.

Com isso, é primordial que o docente proporcione ao aluno do Ensino Fundamental I momentos de contato com textos diversos. Esse contato com os textos faz com que o aluno se aproprie de arranjos linguísticos valorizados socialmente, ou seja, da norma prestigiada socialmente, tendo em vista que, principalmente os alunos pertencentes a grupos sociais mais marginalizados, eles já chegam à escola com arranjos linguísticos, com uma gramática do uso popular, cuja estrutura é simples, às vezes, bastante distante da língua padrão. Assim, a aula de produção de texto ganha importância, pois é o momento de oferecer ao aluno outros arranjos linguísticos, que são fundamentais para a ascensão social, sem contar os benefícios no desenvolvimento das competências cognitivas.

No entanto, o texto, enquanto enunciado concreto, não pode ser utilizado como objeto mudo no ensino. A aula de produção textual a partir de textos configura-se como o encontro de sujeitos, de consciências e de valorações. É um momento de encontro com o outro e, a partir desse encontro, o sujeito aluno se transforma, pois é convocado a ocupar lugares discursivos em relação ao texto/outro sujeito.

Ademais, o ensino de produção de texto nas últimas séries dos anos iniciais do Ensino Fundamental, numa perspectiva dialógica, precisa considerar os seguintes aspectos:

(i) O texto e seu papel na aquisição de competências a serem desenvolvidas pelos alunos das últimas séries dos anos iniciais do Ensino Fundamental, considerando os usos da língua escrita. Nesse aspecto, entram as questões postas pela BNCC, pois os anos iniciais do Ensino Fundamental devem proporcionar ao aluno "a relação com múltiplas linguagens, incluindo os usos sociais da escrita e da matemática, permitindo a participação no mundo letrado e a construção de novas aprendizagens, na escola e para além dela" (BNCC, 2017, p.58). Esse documento ainda estabelece que é nessa fase que "ampliam-se também as experiências para o desenvolvimento da oralidade e dos processos de percepção, compreensão e representação, 
elementos importantes para a apropriação do sistema de escrita alfabética e de outros sistemas de representação [...]" (p.58). Essas e outras competências são adquiridas a partir do contato com textos, ou seja, não há ensino de linguagem sem a presença de textos. Daí a importância de professores e alunos tomarem consciência da natureza multiforme da linguagem, que ganha forma em textos diversos.

(ii) O texto se materializa em gêneros discursivos e estabelece relações com as esferas sociais. O ensino de texto a partir da perspectiva dialógica leva em conta a interação, a relação entre o verbal e o não-verbal, o papel do contexto na organização do texto, a influência que o meio social exerce nas escolhas linguísticas. O texto aqui é concebido como produção da atividade humana, situada em um espaço e em um tempo específicos. Nesse sentido, o papel do professor, enquanto mediador, é o de recuperar, situar o texto (objeto de ensino) em seu momento de construção. Os textos se encontram na sociedade, em práticas reais de comunicação, circulam com estruturas, estilos e temáticas específicas, ou seja, em formas de gêneros discursivos. Trabalhar com o ensino de texto é lidar com a vida real, com as práticas de comunicação reais. Essa perspectiva exclui a prática do ensino de texto a partir de frases isoladas ou de palavras descontextualizadas e, principalmente, do ensino focado nas nomenclaturas gramaticais. Ao mesmo tempo, ao considerar as esferas sociais de produção do gênero, o ensino da produção de texto, na perspectiva dialógica, leva em conta a relação orgânica do texto com a sociedade, a ideologia, o poder, a política, os valores, os preconceitos, as formas de resistências, as subjetividades etc. $\mathrm{O}$ texto é o produto da interação entre sujeitos e ocorre em determinado contexto. Todas as temáticas possíveis que podem/devem ser trabalhadas no Ensino Fundamental só são possíveis a partir de textos, pois são eles que materializam as temáticas sociais.

(iii) O texto é palco de alteridades, de encontros e desencontros de vozes, pois todo texto é uma resposta a outros textos. Esse aspecto do texto traz implicações importantes para o ensino de produção textual, exigindo de professores e alunos uma postura ativa nesse processo. Assim, a prática de produzir textos precisa desenvolver competências voltadas ao manejo em lidar com pontos de vista alheios, em tratar com a palavra do outro etc. O texto, nesse sentido, é palco de uma orquestração de vozes. Produzir textos é orquestrar vozes diversas na tessitura dos sentidos. Diante disso, essa concepção de texto traz para o ensino a necessidade de se trabalhar, já no Ensino Fundamental, a construção de uma autoria. Texto com autoria é o que 
propõe a perspectiva dialógica. Isso implica criar situações de ensino nas quais o sujeito aluno precisa se situar no tempo e no espaço, tendo consciência de situações comunicativas reais, com destinatários individuais e/ou coletivos reais. Quem é seu outro nesse processo comunicativo? Para quem ele escreve? O que esse outro/destinatário espera? O que ele já sabe? Qual é a linguagem mais adequada para esse texto, considerando a perspectiva do destinatário? Que gênero é adequado para tal comunicação? Questões como essas e outras estão na base do processo de ensino de produção de texto.

(iv) O texto é uma forma composicional, uma construção discursiva e/ou artística - as fronteiras do texto. A perspectiva dialógica não despreza as formas da língua no processo de ensino, mas desloca-as para outros lugares, a saber, o lugar da situação de comunicação, o lugar das intenções subjetivas, o lugar do estilo do gênero, o lugar da construção de sentidos, o lugar das valorações. Assim, exclui-se do ensino de produção de texto o foco na nomenclatura gramatical, priorizando a reflexão sobre o gênero, pois esse apresenta uma composição, uma forma relativamente estável. Cabe ao professor oferecer condições para que o aluno se aproprie dos recursos da língua, visando à construção de textos comunicativamente eficientes. Desse modo, o ensino de orações, frases, parágrafos, estrofes, títulos, por exemplo, é feito considerando os sentidos, as escolhas, a organização, os efeitos construídos, a sonoridade, enfim, o todo do enunciado. Isso implica, ainda, considerar o texto como materialização da língua (morfemas, palavras, frases), portanto, palco de escolhas linguísticas e de constituição de estilos.

(v) O texto é um feixe de elementos que configuram seus sentidos, incluindo coesão, coerência, aceitabilidade, informatividade, situacionalidade, intertextualidade, intencionalidade. Esse aspecto aponta para o texto enquanto uma unidade de sentido complexa. A perspectiva dialógica da linguagem abre a possibilidade de entender o texto a partir do alargamento de fronteiras, ou seja, o texto é uma unidade de sentido, que envolve aspectos múltiplos. Esses aspectos múltiplos - que a linguística textual chama de elementos/propriedades da textualidade, ou seja, aquilo que faz um texto ser um texto - funcionam de forma orgânica, incluindo elementos da materialidade linguística (a coesão, por exemplo) e da situação de comunicação (situacionalidade, por exemplo). Cabe notar que os elementos/fatores da textualidade só são possíveis de serem considerados a partir de uma concepção de texto que considere a inseparabilidade entre elementos verbais e extra-verbais. 
(vi) O texto enquanto objeto de fruição e prazer (o prazer em ler, ouvir e produzir textos). O ensino de produção de texto não pode ser encarado como uma punição para o aluno, principalmente na primeira etapa do Ensino Fundamental I. Nessa etapa do ensino, é fundamental que a escola promova o prazer pelo texto, pela leitura e pela escrita. Assim, o trabalho com o texto na sala de aula precisa ser algo prazeroso, agradável, tendo em vista a criação de hábitos. Para isso, é importante que os professores do Ensino Fundamental I comecem a trabalhar com textos interessantes, que envolvam os alunos e estejam relacionados à vida dos alunos. Além disso, é fundamental que a produção do texto receba um retorno, uma resposta, tendo em vista a valorização do texto produzido, da mensagem produzida. Não é mais concebível a produção de texto na escola com fins puramente avaliativos. Muitos alunos não gostam do trabalho com texto em aula porque o associam à avaliação, à nota. O desafio dos professores é, nessas condições, fazer com que a produção de texto seja algo prazeroso, agradável e recompensador.

(vii) O texto como conhecimento para a ascensão social (o poder advindo das competências em utilizar variados textos em situações reais de comunicação). Esse aspecto marca a intrínseca relação entre os textos e as formas de ação social. Os textos são formas de inter-ação, pressupondo o uso da linguagem em diferentes instâncias sociais. Assim, ao se apropriar de um gênero discursivo, ou seja, ao saber mobilizar determinado texto, o sujeito lança mão de uma tecnologia de interação social. Com os textos, resolvemos conflitos, solicitamos, requeremos, reclamamos, delegamos direitos, instruímos, provocamos emoções diversas, informamos, criticamos, produzimos humor etc. A escola, assim, não pode negar essas formas de ação, possíveis por meio de textos.

(viii) O texto como recurso fomentador do crescimento das capacidades neurológicas (ler, escutar, falar textos simples, medianos e complexos e suas consequências para o desenvolvimento neurológico da criança). Esse aspecto parte do princípio de que a linguagem exerce papel fundamental no desenvolvimento das faculdades neurológicas, sendo o texto um instrumento que precisa ser aprendido. Isso é mais relevante quando consideramos que os alunos das últimas séries dos anos iniciais do Ensino Fundamental estão em intenso processo de crescimento e desenvolvimento da fala e da escrita. Se a escrita é geralmente adquirida na escola; por outro lado, os alunos já chegam à escola sabendo falar. Ocorre que essa fala é marcada pela variedade usada no seu cotidiano e apresenta uma estrutura simples. Desse modo, 
para adquirir estruturas mais complexas, variedades e mais prestigiadas (da fala e da escrita), os alunos precisam entrar em contato com outras possibilidades de uso da língua. 0 exercício/experiência de produzir textos oferece essa possibilidade. Dessa maneira o trabalho adequado com textos diversos no nível de ensino em foco proporciona o desenvolvimento das competências em leitura, escrita, fala e escuta.

\section{Considerações finais}

Diante dos aspectos discutidos, em síntese, podemos considerar a importância do texto, visto que, conforme pensa Bakhtin (2011), o texto representa a realidade imediata do pensamento e das experiências da vida. Assumir esse ponto de vista nos leva a defender que a prática de ensino em perspectiva dialógica possibilita o trabalho de produção textual caracterizada como um processo interacional, que envolve o sujeito aluno, seus mundos, suas razões, suas emoções, suas necessidades comunicativas, seu modo particular de falar e o modo de falar exigido pela escola. Isso significa que o trabalho da escola deve ser bem mais amplo do que apenas propor exercícios escolares, pois deve estender o ensino da escrita para atividades sociais que demandem o uso dessa modalidade de linguagem em outras áreas sociais, nas quais o agir humano se efetiva em forma de texto.

Trabalhar com texto em tal perspectiva contribui para que o aluno exerça seu ponto de vista crítico, através de um conjunto de arranjos não apenas linguísticos, mas também discursivos, enunciativos, cognitivos etc. Isso constitui uma maneira de a escola realizar um trabalho em que apresente ao aluno aspectos da heterogeneidade da linguagem, como as diversas variedades linguísticas que se originam nas diversas esferas sociais. E também fazer com que esse aluno considere relevantes e legítimas essas diferentes variedades, conscientizando-os da igualdade de prestígio existente entre toda e qualquer modalidade linguística. Ademais, esse trabalho pedagógico deve não só visar ao ensino da modalidade escrita, como também da modalidade oral, dado que essa também representa um processo de construção textual.

É a partir desse olhar pedagógico em perspectiva dialógica que pensamos e propomos a realização de uma aula de produção de texto como o lugar de encontro de sujeitos, de pontos de vista, de valorações históricas, culturais, axiológicas, ideológicas etc. Pensando desse modo, 
nos afastamos daquelas práticas de ensino que consideram o texto somente como um produto da lógica do pensamento do autor, ou como resultado da imanência que principia nas teorias estruturalistas. Sendo assim, a ideia de encontro efetiva a transformação que convoca os sujeitos alunos a ocuparem lugares discursivos para enunciar e assumir posições que constituem suas tomadas de consciência nas práticas de interação sociais.

Portanto, ao pensar o ensino de produção textual como uma prática dialógica, chegamos à conclusão que responde à nossa pergunta de pesquisa e aponta para os seguintes resultados: (1) são os usos sociais da língua escrita que demandam as competências necessárias no processo de aquisição da linguagem escrita; (2) são as materializações de gêneros discursivos em textos que estabelecem as relações e a construção de competências linguístico-discursivas nas esferas sociais; (3) a materialização do gênero discursivo em texto compreende a instância de orquestração de vozes das quais sobressaem a construção de entonações apreciativas e autorias; (4) o texto compreende não apenas uma forma linguística, mas também uma forma discursiva, que demanda do aluno-escritor um posicionamento em razão da operação de vozes sociais; (5) o texto se configura como um feixe de elementos sintático, semântico, pragmático e discursivo, dos quais se erigem um conjunto de apreciações e valorações em razão da demanda comunicativa; (6) o texto configura um lugar para a atuação e fruição do prazer, bem como o lugar de acabamento da atividade estética; e (7) o texto constitui uma instância fomentadora da criação de capacidades neurológicas, sobretudo as que propiciam as habilidades de ler, escrever e escutar no processo de desenvolvimento da criança.

\section{Referências}

ANTUNES, I. Aula de Português: encontro \& interação. São Paulo: Parábola Editorial, 2003.

BAKHTIN, M. Estética da criação verbal. Trad. Paulo Bezerra. São Paulo: Editora WMF, 2011.

BRASIL. Secretaria da Educação Fundamental. Parâmetros Curriculares Nacionais: terceiro e quarto ciclos do Ensino Fundamental - Língua Portuguesa. Brasília: MEC/SEF, 2001.

BRASIL. Base Nacional Comum Curricular. Brasília: MEC, 2017. Disponível em: http://basenacionalcomum.mec.gov.br/images/BNCC_20dez_site.pdf. Acesso em: 22 abr. 2017. 
DOLZ, J., NOVERRAZ. M.; SCHNEUWLY, B. Sequências didáticas para o oral e a escrita: apresentação de um procedimento. In: Rojo, R.; Sales G. (orgs.) (trad.). Gêneros orais e escritos na escola. Campinas: Mercado das Letras, 2004, p.81-108.

KOCH, I. G. V. Desvendando os segredos do texto. São Paulo: Cortez, 2006.

MARCUSCHI, L. A. Produção textual, análise de gêneros e compreensão. São Paulo: Parábola Editorial, 2008.

OLIVEIRA, A. F. F. A construção de estratégias argumentativas no Tribunal do Júri: uma proposta dialógico-discursiva. 2019. 250f. Tese (Doutorado em Linguística), Universidade Federal da Paraíba, João Pessoa, 2019.

SOBRAL, A. Dialogismo e interação. In: SOBRAL, A. Do dialogismo ao gênero: as bases do pensamento do Círculo de Bakhtin. Campinas, SP: Mercado das Letras, 2009.

VOLOCHÍNOV, V. N. A construção da enunciação e outros ensaios. Org. e Trad João W. Geraldi. São Paulo: Pedro \& João, 2013.

VOLÓCHINOV, V. Marxismo e filosofia da linguagem: problemas fundamentais do método sociológico na ciência da linguagem. Trad. Sheila Grillo e Ekaterina Vólkova. São Paulo: Editora 34, 2017.

Recebido em abril 2020.

Aprovado em dezembro 2020. 